\title{
Focus on Research
}

A column sponsored by the ABC Research Committee

Priscilla S. Rogers, Editor

University of Michigan Business School, Ann Arbor

In This Issue:

\section{Research Think Tank: "Complexifying" International communication and Communication Technology}

Gail Fann Thomas

Former Vice Chair, ABC Research committee

Naval Postgraduate School, Monterey, California

RESEARCHERS WITHIN THE ABC are an eclectic group, scattered geographically and unusually varied by discipline. They draw from diverse theoretical frameworks and regularly publish in the journals of other fields and academic associations. While ABC publications and conferences have long provided formal opportunities for dialogue, occasions for informal, face-to-face discussions-particularly with Association colleagues who work from different perspectiveshave, until recently, been a matter of personal initiative. This changed when former $\mathrm{ABC}$ Research Committee Chair, Jone Rymer, introduced the Research Roundtable, a conference event allowing researchers to share questions and concerns emerging from their research-in-progress. To complement the Roundtable and to provide another venue for intimate dialogue among researchers from diverse disciplines within the Association, the Research Think Tank was introduced as a forum in which experienced $A B C$ researchers could challenge each other to think in new ways about emerging research 
issues while enlarging their network of research colleagues within the Association. "By meeting once or twice in an informal, intimate small-group setting," said Research Committee Chair Priscilla Rogers, "perhaps we, as $A B C$ researchers, can realize more value and potential in our diversity and thereby use our diversity to explore together the complexity of our field."

\section{History of the Think Tank}

Supported by the ABC Board and sponsored by the Research Committee, the first ABC Think Tank was held in November 1994 at the International Conference at San Diego State University's Faculty Club. Through a series of structured brainstorming exercises, facilitated by Susan Kleimann, attending researchers addressed the question "What is significant about significant research?" Resulting was a list of sources that have inspired $A B C$ researchers in their work and categorized characteristics of significant research (Rogers, March 1995; Rogers \& Sherblom, June 1995).

Although the Think Tank was originally conceived as a one-time event, the Research Committee decided to try it again at the $\mathrm{ABC}$ International Conference in Chicago. Held at the University of Chicago Executive Education Center, the 1996 Research Think Tank was intended to be less structured procedurally, but more focused topically than the first Think Tank. As John Sherblom, one of the Think Tank facilitators, explained, "We hoped not only to identify, but also to 'complexify' significant research questions." In other words, rather than generating a linear, systematic, and tightly worked-out research agenda, the purpose was to "complexify" relevant research questions by teasing out complexities from the variety of disciplinary perspectives represented. The result was intended to be a collaborative, multidimensional outcome that would allow each participant to take away one or two new ideas for thinking about his or her own research.

\section{Research Think Tank Focus and Participants}

To explore complex differences in approachs and procedures, the 1996 Think Tank participants focused around two critical areas of communication research: international communication and communication technology. Participants identified several key research questions in these areas and shared their individual methodological approaches, 
and theoretical frameworks. A kaleidoscope of perspectives included, but was not limited to, history, rhetoric, linguistics, management, philosophy, social constructionist, and critical theory. Four participants from outside the United States were quintessential to the dialogue, bringing into the idea pool non-American and non-Western views. Participating researchers were: Rebecca Burnett, Geoff Cross, Linda Driskill, Gail Fann Thomas, Janis Forman, Christine Kelly, Bobbie Krapels, Kitty Locker, Leena Louhiala-Salminen, Jeanette Martin, Charles Mirjaliisa, Tuija Nikko, Karen Powell, Priscilla Rogers, Jone Rymer, William Sharbrough, John Sherblom, Jim Suchan, Joo-Seng Tan, Charlotte Thralls, and Michele Zak.

\section{The Process}

To provide a shared basis for discussion, the 22 Think Tank participants read two articles before the event: "Face-to-Face Versus Computer-Mediated Communication: A Synthesis of the Experimental Literature" (Bordia, 1997) and "Yin/Yang Principle and The Relevance of the Externalism and Paralogic Rhetoric to Intercultural Communication" (Yuan, 1997). With these articles as a shared foundation, Think Tank participants broke into subgroups: one group focusing on international communication, the other on communication technology. Linda Driskill, guest editor for the July 1997 Journal of Business and Technical Communication special issue on International Communication, facilitated the subgroup on international communication; John Sherblom, former editor of The Journal of Business Communication, facilitated the subgroup on communication technology. After 90 minutes, these groups met together, summarized their subgroup discussions, looked for connections, and drew conclusions. Below are some of the key ideas that emerged from this process.

\section{International Communication}

The Think Tank subgroup focusing on international communication drew a number of conclusions and raised some questions challenging our research in this area, including the following:

1. Context, process and product should all be considered in international communication. Cultural values are embedded in business communication products (such as business letters, advertisements, Web sites, manuals, annual reports or policy statements) and the 
processes for formulating these products are embedded with cultural values. So too, local and national business practices can both facilitate and constrain communication. Therefore, as Courtis (1997) illustrates in his article, "Corporate Annual Report Graphical Communication in Hong Kong: Effective or Misleading," researchers must consider cultural values, historical factors, and organizational norms when studying communication. Related questions for research include: What are the cultural influences on communication processes and the resulting products? How might we reconceptualize traditional communication processes and products in light of cultural differences?

2. Our research is driven by cultural biases. An individual researcher's basic assumptions, research questions, data collection and interpretations are driven by his or her cultural biases. Identifying and articulating these biases allow us to see the limitations of our research and open us to new possibilities. Important questions for researchers include: What are our underlying assumptions, as individuals and as business communication researchers? How do these assumptions shape and bias our research?

3. Cultural identities and discourse communities are multidimensional. National, cultural, social, and religious influences all construct our identities, as individuals, groups, and societies. Moreover, as Graves (1997) discusses in his article, "'Dear Friend(?)': Culture and Genre in American and Canadian Direct Marketing Letters," discourse, in turn, shapes and is shaped by constructed identities. Related questions of concern for researchers include: How are language, ethnicity, class and other influences shaping our identities? How will these identities influence our diverse discourse communities? How do contingencies best communicate with one another? And finally, in light of these questions, what are the implications for teaching business communication in colleges, universities, and within business organizations?

\section{Communication Technology}

Taking a somewhat different tack, the subgroup dealing with communication technology identified four research areas:

1. Technology shapes and is shaped by discourse. As technology reshapes the way we organize, it in turn seems to be altering the 
basic elements of communication-who, what, where, when, and how. Moreover, as technologies shape new forms of discourse, so too new forms of discourse drive technology needs. Yet, we know little about how computer communication technologies affect organizational relationships, business processes, and organizational design.

2. Technology impacts fundamental communication processes and products. Technological innovation forces us to rethink our approach to topics such as influence, power, persuasion, group processes, the job search, written communication, oral presentations, and hierarchical relationships. Emerging questions include: How does technology affect interactivity in business writing, presentations, and meetings? How are traditional communication processes and products being transformed as a result of technology?

3. Technology does not exclude silence as a form of communication. Silence, long acknowledged as an important facet of communication, also relates to technology. We do not know, however, what role silence plays in technologically mediated communication, or how silence is enlisted and interpreted by those involved.

4. Technology facilitates and constrains communication. New communication patterns seem to be developing as a result of new technologies, but our research is still rather lean in this area. We need to explore how communication is not only enabled but also constrained as a result of new technologies (e.g. Dickson et al., 1997).

\section{Connecting International Communication and communication Technology}

Together, the Think Tank subgroups identified the following connections between intercultural communication and communication technology, which should be accounted for in our research.

1. Culture and language are influencing media. Globalization is calling into question assumptions regarding communication media. New technology allows us to expand the boundaries of communication: to readily transcend cultural boundaries and geographical borders, challenging traditionally held notions. (A good example of this premise is found in Louhiala-Salminen's (1997) "Investigating the Genre of a Business Fax: A Finnish Case Study," which shows 
how the business fax is constituted by and constitutes intercultural social practices.)

2. Technology is redefining discourse communities. As technology crosses national and cultural borders, it impacts interactions within and among discourse communities. How exactly, we have yet to explore.

3. New forms of cross-cultural discourse will influence new technologies. We can expect continued technological innovation to be driven in part by an increasing need for more cross-cultural, global interaction.

4. Silencing and voicing within organizations will be transformed as a result of new technologies. Cultural, political, gender and social issues will influence and be influenced by new technologies. So, too, silencing and voicing will be facilitated and constrained by new technologies as well as open to interpretation as technology and human interaction among various cultures and subcultures evolve.

\section{Implications for Researchers}

Finally, Think Tank participants drew the following overall conclusions:

1. As part of the research process, $A B C$ researchers should articulate how their cultural biases both limit and enable their scholarly work.

2. Collaboration is essential for the kind of multidimensional studies needed on intercultural and technological communication. Complex questions may require multi-disciplinary teaming of researchers.

3. Technology is creating new opportunities for $A B C$ researchers to collaborate, opportunities that $A B C$ researchers need to use to a far greater extent.

4. The definitive theoretical constructs for business communication research in the areas of international communication and communication technology have yet to be identified.

The experience of the 1996 Research Think Tank suggests that our varied perspectives and backgrounds may uniquely equip us to investigate complex technological and cultural communication issues, par- 
ticularly if we continue to strengthen our collaborative relationships within the $\mathrm{ABC}$.

\section{References}

Bordia, P. (1997). Face-to-face versus computer-mediated communication: A synthesis of the experimental literature. The Journal of Busmess Commumication 34(1), 99-120.

Courtis, J. K. (1997). Corporate annual report graphical communication in Hong Kong: Effective or misleading? The Journal of Business Communication 34(3), 269-315.

Dickson, G. W., DeSanctis, G., Poole, M. S., \& Jackson, B. M. (1997). Help or hindrance? The role of communication technologies in changing organizational form. Acadeny of Management Best Paper Proceedings, 303-307.

Graves, R. (1997). "Dear friend(?)": Culture and genre in American and Canadian direct marketing letters. The Journal of Business Communication 34 (3), 232-252.

Louhiala-Salminen, L. (1997). Investigating the genre of a business fax: A Finnish case study. The Journal of Business Communication 34(3), 316-333.

Rogers, P. S. (March 1995). What sources have inspired our research? Business Communication Quarterly 58(1), 57-60.

Rogers, P. S. \& Sherblom, J. C. (June 1995). What are the characteristics of significant research? Business Communication Quarterly 58(2), 56-61.

Yuan, R. (1997). Yin/yang principle and the relevance of externalism and paralogic rhetoric to intercultural communication. Joumal of Business and Technical Communication $11(3), 297-320$.

Address correspondence to Gail Fann Thomas, Department of Systems Management, Naval Postgraduate School, 555 Dyer Road, Monterey CA 93943 (e-mail: gthomas"' navpgs.navy.mil). 